\title{
Contaminação por metais traço em mexilhões Perna perna da costa brasileira
}

\author{
Trace metal contamination in mussel Perna perna from brazilian coast
}

\author{
Micheli da Silva Ferreira ${ }^{\mathrm{I}^{*}}$ Eliane Teixeira Mársico ${ }^{\mathrm{I}}$ Carlos Adam Conte Junior ${ }^{\mathrm{I}}$ \\ Aguinaldo Nepomuceno Marques Júnior ${ }^{I I}$ Sergio Borges Mano \\ Sergio Carmona de São Clemente ${ }^{\mathrm{I}}$
}

- REVISÃO BIBLIOGRÁFICA -

RESUMO

Os metais traço apresentam grande toxicidade quando presentes em teores elevados nos organismos humano $e$ animal. No ambiente aquático, alguns elementos formam compostos orgânicos que bioacumulam nos tecidos de organismos vivos. Os moluscos bivalves se destacam, pois possuem grande participação na dinâmica de contaminantes metálicos no ambiente marinho devido à capacidade de concentrá-los em níveis mais elevados que na água. Os mexilhões são moluscos bivalves que constituem bons indicadores de biodisponibilidade de metais, sendo amplamente utilizados como biomonitores em ecossistemas aquáticos. No Brasil, a espécie de mexilhão Perna perna é o mais cultivado devido à importância na alimentação de grande parte da população das regiões costeiras. Portanto, o consumo de mexilhões pode representar um risco à saúde humana quando proveniente de locais contaminados com metais traço, o que reforça a importância de se conhecer os teores desses elementos nos ambientes que fornecem alimento ao Homem. Devido à constante busca pela qualidade ambiental associada à utilização do mexilhão $\boldsymbol{P}$. perna como biomonitor e como alimento, é importante conhecer o panorama de contaminação do território nacional a fim de auxiliar na prevenção de intoxicação por metais traço pelo consumo desse molusco por grande parte da população brasileira.

Palavras-chave: contaminação, moluscos, litoral brasileiro.

\section{ABSTRACT}

Trace elements are considered toxic in high levels for human and animal organisms. In aquatic environment, some elements can form organic compounds and tend to bioaccumulate in organisms tissues. Bivalve mollusks participate on the metallic contaminants dynamics in aquatic environment due to capacity in concentrate trace elements in their soft tissues in higher levels than in water. Mussels are mollusks widely used as bioindicators of trace metal pollution in coastal areas because they can accumulate various elements as filter-feeders. In Brazil, Perna perna is one of the most commonly consumed bivalve mollusks and the most cultivated in coast regions. Therefore, the consumption of mussels may be a potential risk for human health, which enhances the importance to know trace metal levels in environment that provides food to humans. Due to constantly search for environmental quality and the use of mussels as food and often employed to monitor metal pollution in sea, it is of great interest and importance an overview of metallic contamination in national territory to assist in prevention of intoxication by trace elements.

Key words: contamination, mollusks, brazilian coast.

\section{INTRODUÇÃO}

Os moluscos bivalves, especialmente os mexilhões, são responsáveis por parte da dinâmica de poluentes no ambiente marinho em função da capacidade em concentrar metais traço em níveis mais elevados que na água em várias ordens de grandeza e sobreviver em ambientes contaminados. Estes organismos são utilizados como biomonitores e indicadores de qualidade ambiental, devido à característica filtradora de alimentação, absorvendo e retendo partículas sólidas, entre os quais vários poluentes como os metais traço (RAINBOW, 1995).

\footnotetext{
ILaboratório de Controle Físico-Químico, Departamento de Tecnologia de Alimentos, Faculdade de Veterinária, Universidade Federal Fluminense (UFF), Rua Vital Brazil Filho, 64, 24230-340, Niterói, RJ, Brasil. E-mail: micheliferreira@hotmail.com. *Autor para correspondência.

IIDepartamento de Biologia Marinha, Instituto de Biologia, UFF, Niterói, RJ, Brasil.
} 
Os mexilhões são os organismos invertebrados mais estudados no mundo devido a características como comportamento séssil, resistência a alterações ambientais e importância econômica em várias regiões do planeta (RESGALLA et al., 2008).

No Brasil, os mexilhões são consumidos por grande parte da população de praticamente todas as regiões costeiras. O cultivo de algumas espécies, atividade denominada mitilicultura, possui importância econômica expressiva em determinadas regiões brasileiras, como no estado de Santa Catarina. Dentre as diferentes espécies de mexilhão, o Perna perna é o mais cultivado e mais importante da costa brasileira, pois atinge os maiores tamanhos, cresce relativamente rápido, possui alta taxa de produção, é nutritivo e facilmente coletado (BARAJ et al., 2003). A extensão da costa brasileira, a rápida industrialização e o desenvolvimento econômico nas regiões costeiras resultam na utilização dos estuários para despejo de efluentes urbanos e industriais, que podem conter metais traço. Esse fato representa uma contínua introdução desses poluentes em ambientes estuarinos e costeiros oriundos de rios, lixiviação, escoamento das águas de regiões industrializadas, com consequente contaminação dos organismos marinhos e do ser humano que os consome.

Os metais, quando presentes em elevadas concentrações, apresentam toxicidade tanto no organismo humano quanto no animal. Um exemplo marcante ocorreu, na década de 50, em Minamata, no Japão, na qual toda uma geração desenvolveu sintomas neurológicos e efeitos teratogênicos (FUJIKI \& TAJIMA, 1992). Teores de metais abaixo do estabelecido por agências internacionais também vêm sendo associadas a problemas à saúde humana. Baixas concentrações de chumbo e cádmio foram associadas ao aumento da prevalência de doença arterial periférica na população americana (NAVASACIEN et al., 2004). Diversos outros problemas de saúde como perda de memória, déficit de atenção, distúrbios sensoriais, problemas nos sistemas motor, renal, cardiovascular, imune e reprodutivo, doença de Alzheimer e de Parkinson, entre outros, vem sendo associados a baixas concentrações de mercúrio em alimentos (ZAHIR et al., 2005).

Determinar as concentrações dos contaminantes nos organismos marinhos proporciona o conhecimento da biodisponibilidade dos metais traço nos diferentes ecossistemas, o que permite avaliar os riscos potenciais aos quais a população está exposta, principalmente através da alimentação (GALVÃO et al., 2009). Portanto, o objetivo deste estudo foi traçar um perfil do grau de contaminação por metais traço em mexilhões Perna perna em diferentes sistemas aquáticos na costa sul e sudeste brasileira através da revisão de literatura. $\mathrm{O}$ estudo pontuou características biológicas desses organismos que os tornam importantes no monitoramento e na prevenção de possíveis contaminações humanas por metais traço. $\mathrm{O}$ conhecimento reunido nesse estudo poderá auxiliar na delimitação de áreas do litoral brasileiro com maior histórico de contaminação por elementos traço, fornecendo ferramentas que permitam uma avaliação de risco e a criação de estratégias de monitoramento e controle ambiental.

Metais traço no ambiente e programas de monitoramento

Os metais podem manter-se em solução na água, ser adsorvido no sedimento ou ser absorvido pelos organismos (GALVÃO et al., 2009). Para monitoramento da poluição aquática, realiza-se frequentemente o monitoramento biológico, no qual são utilizados organismos para a detecção da biodisponibilidade de metais na coluna d'água e/ou na água intersticial do sedimento. Os moluscos bivalves se destacam como biomonitores por serem capazes de acumular metais em altas concentrações em seus tecidos, em ordens de grandeza mais elevadas que na água do mar. Desde 1975, os moluscos bivalves são os organismos marinhos propostos para programas de biomonitorização de poluição por metais traço de águas costeiras marinhas. Em 1986 foi iniciado o mais extenso programa de monitoramento ambiental contínuo nos EUA denominado Mussel Watch Program. O programa utiliza várias espécies de mexilhões e ostras, além de sedimento, para monitoramento das distribuições temporal e espacial de mais de 100 contaminantes químicos nas regiões costeiras e estuarinas dos EUA (KIMBROUGH et al., 2008). Embora o programa Mussel Watch seja bem sucedido em sua proposta, com uma abrangência territorial e de contaminantes, os locais monitorados regularmente no programa se limitam à América do Norte e Central e as espécies de bivalves utilizadas não ocorrem naturalmente na América Latina (GALVÃO et al., 2009). No Brasil, a Companhia Ambiental do Estado de São Paulo (CETESB) possui um programa de monitoramento para as águas costeiras de São Paulo de acordo com o uso pretendido. O programa é adequado à atividade desenvolvida, por meio de análises semestrais de água e sedimento, mas não abrange todo o território nacional.

A expansão do cultivo de moluscos bivalves permite associar as atividades de mitilicultura com monitoramento ambiental, gerando resultados

Ciência Rural, v.43, n.6, jun, 2013. 
de ecotoxicologia, que conferem certificado de qualidade ao pescado produzido (GALVÃO et al., 2009). Desta forma, e baseado em experiências como o programa Mussel Watch, torna-se necessário e possível o desenvolvimento e a implementação de um programa de biomonitoramento utilizando os moluscos bivalves que o Brasil produz em maior escala, o mexilhão $\boldsymbol{P}$. perna.

\section{Utilização do mexilhão como biomonitor}

Biomonitores são organismos utilizados para quantificar a presença de contaminantes no ambiente, através da bioacumulação tecidual, informando sobre a variação temporal e geográfica na concentração do contaminante no meio aquático. Para que um organismo seja considerado biomonitor deve possuir hábitos sedentários, ocorrência durante todo o ano no ambiente, facilidade de coleta, resistência e tolerância a variações de salinidade (RESGALLA JR. et al., 2008). Essa tolerância se baseia na estratégia dos bivalves em formar grânulos mineralizados nos espaços extracelular e intracelular e realizar a complexação com metaloproteínas para a estocagem e/ou detoxificação de metais (MARIGOMEZ et al., 2002).

No bivalve primitivo, as brânquias possuíam função respiratória e, em menor proporção, função alimentar, coletando partículas do substrato depositado no sedimento, o que constituía uma via de exposição direta às substâncias tóxicas. Conforme a evolução da espécie, um novo sistema branquial se desenvolveu, passando a filtrar as partículas em suspensão para alimentação (GALVÃO et al., 2009). $\mathrm{Na}$ coluna d'água, os metais se associam às partículas em suspensão que se depositam no sedimento, que pode ser remobilizado disponibilizando os metais novamente para a coluna d'água e, consequentemente para os organismos filtradores. Como os bivalves podem filtrar grandes quantidades de água diariamente, podem acumular contaminantes inorgânicos nos tecidos em concentrações de 1.000 a 10.000 vezes maior do que as encontradas na fonte de exposição(UNEP, 2004).

O grupo mais abundante de bivalves é o dos mexilhões ou mitilídeos, termo utilizado na denominação de diferentes espécies da família Mytilidae. Os mexilhões ocorrem em costões rochosos (P. perna) e em estuários (Mytella falcata e M. guyanensis) e são utilizados na alimentação humana. Contudo, existem diferenças na magnitude de bioacumulação pelos mexilhões em diferentes regiões devido à quantidade de chuvas, tipos de ventos, correntes marinhas e temperatura entre regiões tropicais e subtropicais e as regiões temperadas.

\section{Mexilhão Perna perna}

O termo mexilhão é mais aplicado às espécies empregadas na alimentação humana e consumidas, geralmente, por populações que vivem em áreas costeiras, sendo bastante popular em muitos países do mundo. Na família Mytilidae, existem diversas espécies comestíveis e de importância comercial, dentre as quais se destaca o gênero Perna, sendo a espécie Perna perna o maior mitilídeo brasileiro (KLAPPENBACH, 1964), ocorrendo em abundância no Brasil, do litoral do Espírito Santo ao litoral de Santa Catarina(WALLNER-KERSANACH \& BIANCHINI, 2008).

O mexilhão $\boldsymbol{P}$ perna é uma espécie originária do continente africano, de onde há registro de fósseis de 115 mil anos. Provavelmente, os responsáveis pela dispersão do $\boldsymbol{P}$. perna pelo mundo foram os cascos de navios mercantes (FERNANDES et al., 2008). No Brasil, também foram os grandes navios, podendo ter sido através da "água de lastro" (HENRIQUES et al., 2001). Os mexilhões se fixam em qualquer substrato rígido como concreto $\mathrm{e}$ estruturas de ferro formando "colônias" e, na natureza, se fixam aos costões rochosos, formando "bancos naturais". A maior concentração dos mexilhões ocorre nas rochas localizadas na região entremarés, até um metro de profundidade, onde é mais intensa a fixação de indivíduos jovens. Os bancos naturais são um rico ecossistema, pois abrangem, além dos mexilhões, grande número de organismos vegetais e animais, como cracas e pequenos caranguejos e algas (FERNANDES et al., 2008).

Pelo fato do mexilhão $\boldsymbol{P}$. perna ser um dos mais abundantes na costa brasileira, é a espécie amplamente utilizada como indicadora do grau de poluição marinha. Além disso, apresenta diversas características desejáveis para um biomonitor, como tamanho razoável para coleta e estudo, biologia e ecologia conhecidas e, sobretudo, capacidade de acumular contaminantes do ambiente em que vive (RESGALLA Jr. et al., 2008; WALLNERKERSANACH \& BIANCHINI, 2008). Entretanto, considerações descritas por ANANDRAJ et al. (2002) são relevantes para compreender a dinâmica de alguns elementos. Os autores observaram que o $\mathrm{Hg}$ e o $\mathrm{Cu}$ acumulados em mexilhões, expostos a esses metais em tanques, foram rapidamente eliminados quando as condições de exposição foram normalizadas. Este fato levou os autores a questionar a habilidade do P. perna em concentrar metais em ambientes onde os teores dos mesmos estejam próximos aos denominados "níveis de base" de metais do local. Embora sejam necessários mais estudos, pode-se inferir que, para 
programas de biomonitoramento de metais traço, a utilização de mexilhões $\boldsymbol{P}$. perna seja mais adequada em ambientes altamente contaminados.

Locais com histórico de contaminação por metais

A Baía de Guanabara, no estado do Rio de Janeiro, é o mais importante estuário do sudeste brasileiro com relação à produtividade, e possui população estimada em cerca de 10 milhões de pessoas, além de mais de seis mil atividades industriais no entorno, dentre as quais 455 consideradas como prioritárias para o controle da poluição pela Fundação Estadual de Engenharia do Meio Ambiente, FEEMA (IBG, 2011). Sua bacia tem sido seriamente afetada pela grande quantidade de poluição oriunda, principalmente, de refinarias e terminais de óleos, esgoto sem tratamento, águas de despejo urbano (runoff urbano) e rural (COSTA et al., 2000). A região vem sendo degradada desde sua colonização, o que vem piorando consideravelmente devido ao desenvolvimento urbano e industrial. Em 1991, foi criado o Programa de Despoluição da Baía de Guanabara (PDBG), com o objetivo de reduzir os índices de poluição da região e a partir da assinatura do Convênio de Cooperação Técnica entre os governos brasileiro e japonês. Técnicos brasileiros da FEEMA e especialistas japoneses, coordenados pela JICA - Japan International Cooperation Agency (Agência Japonesa de Cooperação Internacional) se basearam na experiência bem sucedida de despoluição da Baía de Tóquio e elaboraram o Plano Diretor JICA (BITTENCOURT et al., 2006). A poluição na Baía de Guanabara se manteve estável por mais de 15 anos, período no qual a baía recebia efluentes contendo metais, como o mercúrio oriundo de uma indústria de cloro-álcali nas margens de um de seus tributários (FRANCIONE et al., 2004). Embora esta indústria tenha modificado o processo de produção, a baía continuou a receber águas de diversos rios que atravessam áreas de intensa densidade populacional e de estados altamente industrializados, o que mantém a preocupação permanente sobre a contaminação da baía por metais traço (COSTA et al., 2000). Nesse ecossistema, foram encontradas baixas concentrações de metilHg ao longo da cadeia trófica, o que foi associado ao estado hipereutrófico da baía e à grande quantidade de material particulado em suspensão, ao qual o metilHg tende a adsorver-se ou a se complexar fortemente. Desta forma, os lançamentos desse composto tóxico são diluídos no meio, com consequente redução do tempo de residência na coluna d'água e da disponibilidade biológica (KERHIG et al., 2011). Uma das ações necessárias para a revitalização das águas da Baía de Guanabara é a dragagem dos canais, contaminados com metais traço, compostos orgânicos e microrganismos patogênicos (BARBOSA et al., 2004). No entanto, o destino do rejeito de dragagem constitui uma grande preocupação, pois os contaminantes seriam transferidos para outro local, agravando o problema da poluição ambiental. Por este motivo, as operações de dragagem são enquadradas como atividade potencialmente poluidora, conforme as Resoluções CONAMA no 237/97, que prevê seu licenciamento ambiental, e $\mathrm{n}^{\mathrm{o}}$ 344/04, na qual a atividade é tratada especificamente.

Outro local no estado do Rio de Janeiro que representa um criadouro natural para pescado é a Baía de Sepetiba. Historicamente, a região constitui uma importante área de pesca com suporte econômico e social, onde muitos estudos vêm sendo realizados desde a década de 70 , o que permite uma avaliação das mudanças históricas na concentração dos metais no local. A baía de Sepetiba alberga pequenos estaleiros e dois grandes portos, o Porto de Sepetiba e o de Mangaratiba. Pelo Porto de Sepetiba são transportadas grandes quantidades de minério de ferro, concentrando a carga da costa sudeste da América do Sul. Na década de 90, as atividades de reforma e ampliação das instalações do porto contribuíram com a poluição do local. A dragagem de sedimentos de um canal para permitir a passagem de grandes navios resultou na remobilização de metais depositados no sedimento da baía, disponibilizandoos para a água e a biota (SEMADS, 2001).

A baía de Sepetiba possui um histórico de contaminação por $\mathrm{Cd}$ e $\mathrm{Zn}$ oriundos de indústrias metalúrgicas de fundição de $\mathrm{Zn}$, principalmente da Companhia Mercantil e Industrial Ingá, instalada no início dos anos 60. Em uma das etapas do processo de produção química, a indústria de $\mathrm{Zn}$ utilizava o trióxido de arsênio $\left(\mathrm{As}_{2} \mathrm{O}_{3}\right)$ para a purificação do minério, e este composto alcançava a água pelo despejo industrial e dispersão atmosférica. Todas as formas de As tendem a se acumular no sedimento de fundo, podendo se remobilizar por vários processos e alcançar a biota aquática, como os mexilhões (MAGALHÃES et al., 2001). Embora a Cia. Ingá tenha sido fechada em 1996, existiam na mesma área, cerca de 400 indústrias da mesma natureza (SEMADS, 2001), e o cenário poluidor do parque industrial permaneceu o mesmo entre os anos $80 \mathrm{e}$ 90. O fechamento dessa grande indústria refletiu em mudanças nas emissões de $\mathrm{Cd}$ e $\mathrm{Zn}$, reduzindo as emissões de $\mathrm{Cd}$ pela metade e significativamente as de $\mathrm{Zn}$ (LACERDA \& MOLISANI, 2006). Porém,

Ciência Rural, v.43, n.6, jun, 2013. 
foram encontrados níveis de Zn em ostras da baía três vezes mais altos que os estabelecidos pela legislação internacional, confirmando a contaminação ambiental da baía com este elemento (CARNEIRO et al., 2011). O risco de contaminação na baía aumenta em períodos de chuvas fortes, devido à possibilidade de rompimento dos diques de contenção dos rejeitos, como ocorreu em 1996, liberando toneladas de lama tóxica com altas concentrações de $\mathrm{Zn}, \mathrm{Cd}$, $\mathrm{As}$ e $\mathrm{Pb}$ (MAGALHÃES et al., 2001). Até o fechamento da Ingá Mercantil, a FEEMA (2011) estimou a liberação de cerca de dez milhões de toneladas de $\mathrm{Cd}$ e $\mathrm{Zn}$ para a baía de Sepetiba. Apesar das providências tomadas pela indústria na ocasião dos vazamentos, o cenário requer atenção das autoridades governamentais, pois o passivo ambiental de resíduos tóxicos representa uma ameaça ao equilíbrio ecológico da região (FEEMA, 2011).

Estudos da presença de metais traço em Perna perna Foram pesquisados e citados artigos que abordaram a presença de metais traço, sobretudo em mexilhões $\boldsymbol{P}$. perna no Brasil, principalmente nos ambientes mais impactados pela poluição urbana e industrial. $\mathrm{O}$ resumo dos artigos utilizados para a presente discussão pode ser observado na tabela 1 .

Tabela 1- Estudos sobre metais traço em mexilhões Perna Perna e outros organismos aquáticos nas regiões sul e sudeste do Brasil, com respectivos locais, elementos e autores.

\begin{tabular}{|c|c|c|c|c|c|}
\hline \multicolumn{2}{|l|}{ Local } & Estado & Elemento (s) & Organismo (s) & Autor (es) \\
\hline \multicolumn{2}{|l|}{ Baía de Guanabara } & RJ & metilHg & $\begin{array}{l}\text { Organismos planctônicos, peixes } \\
\text { e mexilhões Perna perna }\end{array}$ & KERHIG et al., 2011 \\
\hline \multicolumn{2}{|l|}{ Baía de Sepetiba } & RJ & $\begin{array}{l}\mathrm{Cr}, \mathrm{Mn}, \mathrm{Fe}, \mathrm{Ni}, \mathrm{Cu}, \mathrm{Zn} \text { e } \\
\mathrm{Se}\end{array}$ & $\begin{array}{l}\text { Ostras (Crassostrea rhizophorae) } \\
\text { e peixes }\end{array}$ & CARNEIRO et al., 2011 \\
\hline \multicolumn{2}{|c|}{ Baía de Guanabara } & RJ & $\mathrm{Hg}$ & Mexilhões Perna perna & $\begin{array}{l}\text { COSTA et al., } 2000 \\
\text { dados de } 1988 \text { e } 1998\end{array}$ \\
\hline \multicolumn{2}{|l|}{ Baía de Sepetiba } & RJ & $\mathrm{Zn}$ e Cd & $\begin{array}{l}\text { Ostras (Crassostrea rhizophorae) } \\
\text { e mexilhões (Perna perna) }\end{array}$ & AMARAL et al., 2005 \\
\hline \multicolumn{2}{|l|}{ Cabo Frio } & RJ & $\mathrm{Zn}$ e Cd & $\begin{array}{l}\text { Ostras (Crassostrea rhizophorae) } \\
\text { e mexilhões (Perna perna) }\end{array}$ & AMARAL et al., 2005 \\
\hline \multicolumn{2}{|l|}{ Baía de Ubatuba } & SP & $\mathrm{Cd}, \mathrm{Cu}, \mathrm{Cr}, \mathrm{Pb}$ e $\mathrm{Zn}$ & Mexilhões (Perna perna) & AVELAR et al., 2000 \\
\hline $\begin{array}{l}\text { Diferentes } \\
\text { costeiras }\end{array}$ & regiões & SP & $\begin{array}{l}\mathrm{Cd}, \mathrm{Pb}, \mathrm{Hg}, \mathrm{As}, \mathrm{Ca}, \mathrm{Co}, \\
\mathrm{Cr}, \mathrm{Fe}, \mathrm{Na}, \mathrm{Se} \text { e } \mathrm{Zn}\end{array}$ & Mexilhões (Perna perna) & CATHARINO et al., 2008 \\
\hline $\begin{array}{l}\text { Diferentes } \\
\text { costeiras }\end{array}$ & regiões & RS & $\begin{array}{l}\mathrm{Hg}, \mathrm{Mn}, \mathrm{Cr}, \mathrm{Cu}, \mathrm{Cd}, \mathrm{Pb}, \\
\text { Fe e } \mathrm{Zn}\end{array}$ & Mexilhões (Perna perna) & BARAJ et al., 2003 \\
\hline $\begin{array}{l}\text { Diferentes } \\
\text { costeiras }\end{array}$ & regiões & $\mathrm{SC}$ & $\begin{array}{l}\mathrm{As}, \mathrm{Ag}, \mathrm{Cr}, \mathrm{Mn}, \mathrm{Ni} \mathrm{Cd}, \\
\mathrm{Cu}, \mathrm{Pb} \text { e } \mathrm{Se}\end{array}$ & $\begin{array}{l}\text { Ostra (Crassostrea gigas) } \\
\text { Mexilhões (Perna perna) }\end{array}$ & CURTIUS et al., 2003 \\
\hline $\begin{array}{l}\text { Diferentes } \\
\text { costeiras }\end{array}$ & regiões & RJ & $\mathrm{Cu}, \mathrm{Zn}, \mathrm{Cd}$ e $\mathrm{Cr}$ & & FRANCIONI et al., 2004 \\
\hline $\begin{array}{l}\text { Diferentes } \\
\text { costeiras }\end{array}$ & regiões & $\mathrm{RS}$ & $\mathrm{Cd}, \mathrm{Zn}, \mathrm{Fe}, \mathrm{Cu}, \mathrm{Pb}$ e $\mathrm{Mn}$ & Mexilhões (Perna perna) & FURLEY, 1993 \\
\hline \multicolumn{2}{|l|}{ Baía de Sepetiba } & RJ & $\mathrm{Cd}$ e $\mathrm{Zn}$ & Ostras (Crassostrea rhizophorae) & $\begin{array}{l}\text { LACERDA e MOLISANI, } 2006 \\
\text { (últimas três décadas) }\end{array}$ \\
\hline
\end{tabular}


COSTA et al. (2000) investigaram os níveis de $\mathrm{Hg}$ em mexilhões $\boldsymbol{P}$. perna da Baía de Guanabara na Urca e na Marina da Glória, em intervalos de 10 anos (1988 a 1998). A Urca é uma área com entrada de águas limpas de onde os mexilhões foram retirados. As águas da Marina da Glória sofrem influência direta da descarga de galerias pluviais provenientes do sul da cidade do Rio de Janeiro, o que acarretou aumento significativo dos níveis de $\mathrm{Hg}$ deste local no intervalo de 10 anos proposto no estudo. Por outro lado, os autores não verificaram diferença significativa entre os níveis de $\mathrm{Hg}$ nos mexilhões coletados na Urca, no mesmo intervalo de tempo, justificando a influência direta de águas oceânicas na contaminação do ambiente marinho e, consequentemente, na biota aquática local.

A concentração de $\mathrm{Cu}, \mathrm{Cr}, \mathrm{Zn}$ e $\mathrm{Cd}$ em mexilhões $\boldsymbol{P}$. perna foi estudada pelos mesmos autores em toda a costa do Rio de Janeiro, incluindo as baías de Guanabara e Sepetiba. Foram encontrados níveis baixos de todos os metais, exceto o $\mathrm{Cr}$ em alguns locais, que excedeu o valor permitido pela legislação brasileira de $0,1 \mathrm{mg} \mathrm{g}^{-1}$ para consumo humano. Em alguns locais da baía de Guanabara, somente três amostras apresentaram valores de $\mathrm{Zn}$ abaixo do limite máximo permitido. No caso do $\mathrm{Cd}$, a expectativa dos autores para áreas com histórico de contaminação pela presença de fontes poluidoras (Baía de Sepetiba e Barra de Guaratiba) apontava para possíveis altos níveis desse elemento. Todavia, essa tendência ocorreu em locais teoricamente menos contaminados, como Ilha Grande e Arraial do Cabo, em fazendas de cultivo de mexilhões. Como não há fontes poluidoras conhecidas no local, os autores atribuíram os altos teores de $\mathrm{Cd}$ à possível contaminação do alimento ou de materiais utilizados no cultivo dos organismos e à provável influência de material contaminado transportado pelas correntes marinhas oriundas do nordeste da Baía de Sepetiba.

Outra região poluída com metais traço é o Norte Fluminense do Rio de Janeiro, na cidade de Macaé, conhecida por produzir cerca de $72 \%$ do petróleo do país. Segundo dados de 2010 do IBGE, Instituto Brasileiro de Geografia e Estatística (2011), a cidade possui quase 207 mil habitantes, o que contribui para a entrada de metais para o sistema via esgoto urbano, além de possuir uma intensa atividade portuária. As concentrações de vários elementos ( $\mathrm{Al}$, $\mathrm{Fe}, \mathrm{Mn}, \mathrm{Cd}, \mathrm{Cr}, \mathrm{Cu}, \mathrm{Ni}, \mathrm{Pb}$ e $\mathrm{Zn}$ ) foram investigadas em mexilhões $\boldsymbol{P}$. perna da Ilha de Santana, situada próxima a uma região portuária de grande movimento em Macaé. Os teores de metais encontrados sugeriram ausência de contaminação na região, exceto para o
$\mathrm{Cu}$, cujos valores foram quatro vezes superiores ao máximo permitido pela legislação brasileira. As altas concentrações de $\mathrm{Al}$ e Fe encontradas foram atribuídas à presença de navios na região que abastecem as plataformas de petróleo da Bacia de Campos, a maior produtora de petróleo no Brasil, contribuindo com a entrada de metais proveniente da oxidação dos cascos dos navios (AMARAL et al., 2005).

Um estudo com ostras (Crassostrea rhizophorae) e mexilhões (P. perna) na costa do Rio de Janeiro foi realizado baseado em um conceito denominado biomonitoramento ativo, tipo de monitoramento que visa diminuir as variações naturais, como a diferença de tamanho entre exemplares(AMARAL et al., 2005). Estudos baseados neste conceito consistem em transferir organismos marinhos de áreas não contaminadas, geralmente fazendas de mexilhões, para áreas poluídas, ou viceversa, e após determinado período de exposição, retorno ao ambiente de origem e posterior análise (GALVÃO et al., 2009). Seguindo esse conceito, os autores supracitados verificaram a habilidade de ostras e mexilhões em bioacumular e depurar $\mathrm{Zn}$ e $\mathrm{Cd}$ em condições naturais. Organismos de uma fazenda em Santa Catarina foram transplantados (1) para a Baía de Sepetiba, região contaminada por metais traço e (2) para Cabo Frio, região sem registros de contaminação ambiental por metais, e determinaram as concentrações de $\mathrm{Zn}$ e Cd durante três meses a cada 30 dias. Os autores verificaram pouca capacidade de depuração ou depuração incompleta dos organismos, apesar de observarem significativa redução do $\mathrm{Zn}$ entre as amostras durante o período do estudo, sugerindo que os metais presentes nos grânulos são mantidos por mais tempo nos tecidos.

Em outro estado do sudeste brasileiro, foram analisadas as concentrações de $\mathrm{Cd}, \mathrm{Cu}, \mathrm{Cr}, \mathrm{Pb}$ e Zn em P. perna coletados na baía de Ubatuba, em diferentes meses. A cidade de Ubatuba está situada no estado de São Paulo e recebe efluentes industriais oriundos da indústria de construção naval e de conservas de peixes. A região também é ocupada por turistas em período de férias, o que aumenta o fluxo de matéria orgânica no esgoto doméstico, aumentando o impacto ambiental de poluição das águas e, consequentemente, dos mexilhões. Os maiores valores de $\mathrm{Pb}$ foram observados durante os meses de férias, sugerindo a origem deste elemento de queima de combustíveis fósseis principalmente de barcos de pesca e de turistas (AVELAR et al., 2000). Ainda no estado de São Paulo, foi realizado um estudo em mexilhões $\boldsymbol{P}$. perna na região costeira por biomonitoramento ativo. Os autores transplantaram

Ciência Rural, v.43, n.6, jun, 2013. 
mexilhões da praia de Cocanha (Caraguacatuba) para regiões próximas ao despejo de efluentes industriais e domésticos, e determinaram as concentrações de $\mathrm{Cd}$, $\mathrm{Pb}, \mathrm{Hg}, \mathrm{As}, \mathrm{Ca}, \mathrm{Co}, \mathrm{Cr}, \mathrm{Fe}, \mathrm{Na}$, Se e $\mathrm{Zn}$ após três meses em cada estação do ano. Após este período, todos os elementos estudados se apresentaram em maiores concentrações. (CATHARINO et al., 2008).

$\mathrm{Na}$ região sul do Brasil, foram estudadas as concentrações de $\mathrm{Hg}, \mathrm{Mn}, \mathrm{Cr}, \mathrm{Cu}, \mathrm{Cd}, \mathrm{Pb}, \mathrm{Fe}$ e $\mathrm{Zn}$ em $\boldsymbol{P}$. perna na costa do Rio Grande do Sul, em locais pouco habitados e considerados livres de contaminação. Apesar disso, os autores compararam mexilhões de áreas distantes e próximas de áreas urbanas. Considerando as duas épocas do ano em que as amostras foram coletadas, verão e inverno, os autores encontraram diferença significativa para $\mathrm{Hg}, \mathrm{Cd}$ e $\mathrm{Pb}$. Além disso, encontraram teores de $\mathrm{Cu}$ e destes mesmos elementos discretamente aumentados em locais próximo às áreas urbanas na época do verão, atribuídos ao maior impacto antropogêncio durante esta época do ano, quando a frequência dos turistas é marcante (BARAJ et al., 2003). Embora os teores de As, $\mathrm{Cd}$ e $\mathrm{Hg}$ tenham permanecido baixos, houve um aumento de $\mathrm{Cd}$, $\mathrm{Fe}, \mathrm{Zn}, \mathrm{Pb}, \mathrm{Cu}$ e $\mathrm{Mn}$ quando comparados com dados de metais em P. Perna determinados no mesmo local 10 anos antes (Hg e Cr não foram pesquisados anteriormente para fins de comparação) (FURLEY, 1993). Este fato demonstra a necessidade do monitoramento e do tratamento de esgoto nas áreas urbanas com a finalidade de prevenir aumento de contaminantes nesta e em outras regiões costeiras.

A qualidade de mexilhões $\boldsymbol{P}$. perna foi investigada no estado de maior produção desses organismos no Brasil, Santa Catarina(CURTIUS et al., 2003). A concentração dos elementos As, Ag, Cr, Mn, $\mathrm{Ni} \mathrm{Cd}, \mathrm{Cu}, \mathrm{Pb}$ e Se encontrava-se abaixo dos limites toleráveis pela FDA e foram semelhantes aos níveis descritos em outros programas de monitoramento internacionais. Entretanto, os autores ressaltam que deve ser realizada uma avaliação complementar em amostras de sedimentos das áreas de cultivo. Em locais com pouca movimentação das águas, a avaliação do sedimento se justifica basicamente devido a (1) mais de $50 \%$ da produção primária sedimentar, (2) maior parte da matéria particulada orgânica ser mineralizada no sedimento, e (3) os produtos de sua decomposição retornarem à coluna d'água, ficando disponíveis novamente aos moluscos. Estudos em lagos marroquinos confirmam esta dinâmica dos metais e a interação entre mexilhões e sedimento, onde houve uma correlação positiva entre as altas concentrações de metais traço nos bivalves estudados dos lagos e as do sedimento local (MAANAN, 2008).

\section{CONCLUSÃO}

Diante da vasta extensão territorial da costa brasileira e da ampla utilização de mexilhões P. perna na alimentação humana, torna-se urgente elaborar e iniciar programas de biomonitoramento em ambientes aquáticos brasileiros a fim de adquirir dados que permitam interpretação adequada para um panorama de contaminação e traçar metas de controle de poluição em locais impactados.

Existe carência de dados científicos relacionados aos teores de metais traço em mexilhões P. perna, molusco que ocorre em abundância no sul e sudeste, regiões costeiras mais populosas do Brasil. Isso demonstra a necessidade de mais estudos com este organismo filtrador, que pode ser utilizado como biomonitor de diversas regiões, com diferentes níveis de contaminação por metais, de modo a salvaguardar a saúde dos consumidores de mexilhão.

Regiões costeiras com conhecida contaminação por metais traço oriundos de fontes industriais e efluentes urbanos, como as baías de Guanabara e Sepetiba, merecem destaque em ações para controle de poluição frente ao histórico de contaminação e a grande importância desses locais para a pesca, tanto como subsistência como para fornecimento de alimento para a população, o que pode se tornar um grave risco à saúde pública.

\section{REFERÊNCIAS}

AMARAL, M.C.R. et al. Bioaccumulation and depuration of $\mathrm{Zn}$ and $\mathrm{Cd}$ in mangrove oysters (Crassostrea rhizophorae, Guilding, 1828) transplanted to and from a contaminated tropical coastal lagoon. Marine Environmetal Research, v.59, p.277-285, 2005. Disponível em: <http://www.sciencedirect.com/science/article/pii/ S0141113604001953>. Acesso em: 18 fev. 2011. doi: 10.1016/j. marenvres.2004.05.004.

ANANDRAJ, A. et al. Metal accumulation, filtration and $\mathrm{O}_{2}$ uptake rates in the mussel Perna perna (Mollusca: Bivalvia) exposed to $\mathrm{Hg}_{2}, \mathrm{Cu}_{2}$ and $\mathrm{Zn}_{2}$. Comparative Biochemistry and Physiology Part C: Pharmacology, v.132, p.355-363, 2002. Disponível em: $<$ http://www.sciencedirect.com/science/article/pii/ S1532045602000819>. Acesso em: 22 abr. 2011. doi: :10.1016/ S1532-0456(02)00081-9.

AVELAR, W.E.P. et al. The marine mussel Perna perna (Mollusca: Bivalvia, Mytilidae) as an indicator of contamination by heavy metals in the Ubatuba Bay, São Paulo, Brazil. Water, Air \& Soil Pollution, v.118, p.65-72, 2000. Disponível em: <http://www. springerlink.com/content/gq958772w8707166/>. Acesso em: 03 abr. 2011. doi: 10.1023/A:1005109801683.

BARAJ, B. et al. Trace metal content trend of mussel Perna perna (Linnaeus, 1758) from the Atlantic coast of southern Brazil. Water, Air \& Soil Pollution, v.145, p.205-214, 2003. Disponível em: <http://www.springerlink.com/content/q601212705554058/>. Acesso em: 18 fev. 2011. doi: 10.1023/A:1023614822121. 
BARBOSA, M.C. et al. Studies of channel sediments contaminated with organics and heavy metals. Journal of Hazardous Materials, v.10, p.29-38, 2004. Disponível em: <http://www.sciencedirect. com/science/article/pii/S0304389404001293>. Acesso em: 12 ago. 2011. doi: 10.1016/j.jhazmat.2004.02.038.

BITTENCOURT, A.L.C. et al. Tribunal de Contas do Estado do Rio de Janeiro. Auditoria operacional no Programa de Despoluição da Baía de Guanabara, 2006. Disponível em: <http://www2.tce. pr.gov.br/xisinaop/trabalhos/auditoria\%20operacional $\% 20$ no $\% 20$ pdbg.pdf. Acesso em: 7 jul. 2006.

CARNEIRO, C.S. et al. Trace elements in fish and oysters from Sepetiba Bay (Rio de Janeiro - Brazil) determined by total reflection $\mathrm{X}$-ray fluorescence using synchrotron radiation. Chemistry and Ecology, v.27, n.1, p.1-8, 2011. Disponível em: <http://dx.doi.org /10.1080/02757540.2010.529249>. Acesso em: 23 abr. 2011. doi: $10.1080 / 02757540.2010 .529249$.

CATHARINO, M.G.M. et al. Biomonitoring of $\mathrm{Hg}, \mathrm{Cd}, \mathrm{Pb}$ and other elements in coastal regions of São Paulo State, Brazil, using the transplanted mussel Perna perna (Linnaeus, 1758). Journal of Radioanalytical and Nuclear Chemistry, v. 278, n.3, p.547-51, 2008. Disponível em: <http://www.springerlink.com/ content/17j3534145200vmt/fulltext.pdf>. Acesso em: 10 fev. 201. doi: 10.1007/s10967-008-1003-1.

COSTA, M. et al. Total mercury in Perna perna mussels from Guanabara Bay -10 years later. The Science of the Total Environment, v.261, p. 69-73, 2000. Disponível em: <http:// www.artigocientifico.com.br/uploads/artc 1151084639 94.pdf> Acesso em: 18 dez. 2010. doi: 10.1016/S0048-9697(00)00596-9.

CURTIUS, A.J. et al. Avaliando a contaminação por elementos traço em atividades de maricultura: resultados parciais de um estudo de caso realizado na ilha de Santa Catarina, Brasil. Química Nova, v.26, n.1, p.44-52, 2003. Disponível em: <http://www. scielo.br/pdf/qn/v26n1/14300.pdf $>$. Acesso em: 10 set. 2011. doi: http://dx.doi.org/10.1590/S0100-40422003000100010.

FERNANDES, F.C. et al. Distribuição mundial e o impacto de sua introdução no Brasil. In: RESGALLA JR., C. et al. O mexilhão Perna perna (L.): biologia, ecologia e aplicações. Rio de Janeiro (RJ): Interciência, 2008. Cap.2, p.26-30.

FRANCIONE, E. et al. Evaluation of Perna perna (Linné, 1758) as a tool to monitoring trace metals contamination in estuarine and coastal waters of Rio de Janeiro, Brazil. Journal of the Brazilian Chemical Society, v.15, n.1, p.103-110, 2004. Disponível em: $<$ http://www.scielo.br/scielo.php?script $=$ sci arttext\&pid $=\mathrm{S} 010$ $350532004000100016 \& \operatorname{lng}=\mathrm{en} \& \mathrm{nrm}=\mathrm{iso}>$. Acesso em: 24 jun 2011. doi: http://dx.doi.org/10.1590/S0103-50532004000100016.

FUJIKI, M.; TAJIMA, S. The pollution of Minamata Bay by mercury, Water Science and Technology, v.25, n.11, p.133-140, 1992. Disponível em: <http://www.iwaponline.com/wst/02511/ wst025110133.htm>. Acesso em: 20 ago. 2003

FUNDAÇ̃̃O ESTADUAL DE ENGENHARIA DO MEIO AMBIENTE (FEEMA). A Baía de Sepetiba. Disponível em: $<$ http://www.feema.rj.gov.br/baia-sepetiba.asp?cat=75>. Acesso em: 19 ago. 2011.

FURLEY, T.H. Utilização do mexilhão Perna perna (Linné, 1758) como bioindicador dos metais pesados cádmio, chumbo, zinco, cobre e manganês do litoral do Rio Grande do Sul
(Brasil). 1993. 131f. Dissertação (Mestrado em Oceanografia biológica) - Instituto de Oceanografia. Fundação Universidade do Rio Grande, RS.

GALVÃO, P.M.A. et al. Bioacumulação de metais em moluscos bivalves: aspectos evolutivos e ecológicos a serem considerados para a biomonitoração de ambientes marinhos. Brazilian Journal of Aquatic Science and Technology, v.13, n.2, p.59-66, 2009. Disponível em: <http://www6.univali.br/seer/index.php/bjast/ article/view/1359/1518>. Acesso em: 24 abr. 2011.

HENRIQUES, M.B. et al. Estimativa do tempo de recuperação de um banco natural do mexilhão Perna perna (Linnaeus, 1758) na Baía de Santos, Estado de São Paulo. Holos Environment, v.1, n.12, p.85-100, 2001. Disponível em: $<\mathrm{http}: / / \mathrm{www}$.periodicos. rc.biblioteca.unesp.br/index.php/holos/article/view/1619/1377>. Acesso em: 2 set. 2010

INSTITUTO BAÍA DE GUANABARA (IBG). Portal da Baía de Guanabara. Disponível em: $<\mathrm{http} / / \mathrm{www}$.portalbaiadeguanabara. com.br/portal>. Acesso em: 27 ago. 2011

INSTITUTO BRASILEIRO DE GEOGRAFIA E ESTATÍSTICA (IBGE). Censo/população. Disponível em: http://www.ibge.gov. br/cidadesat/topwindow.htm?1. Acesso em: 4 set. 2011.

KEHRIG, H.A. Bioconcentração e biomagnificação de metilmercúrio na Baía de Guanabara, Rio de Janeiro. Química Nova, v.34, n.3, p.377-84, 2011. Disponível em: <http:// quimicanova.sbq.org.br/qn/qnol/2011/vol34n3/02-AR10108.pdf>. Acesso em: 15 jul. 2011.

KIMBROUGH, K.L. An assessment of two decades of contaminant monitoring in the nation's coastal zone. Silver Spring, MD.: NOAA Technical Memorandum NOS NCCOS 74, 2008. Disponível em: <http://ccma.nos.noaa.gov/publications/ MWTwoDecades...>. Acesso em: 13 jun. 2011.

KLAPPENBACH, M.A. Lista preliminar de los Mytilidae brasileños com claves para su determinación y notas sobre su distribuición. Anais da Academia Brasileira de Ciências, v.37, supl, p.327-352, 1964

LACERDA, L.D.; MOLISANI, M.M. Three decades of Cd and $\mathrm{Zn}$ contamination in Sepetiba Bay, SE Brazil: Evidence from the mangrove oyster Crassostraea rhizophorae. Marine Pollution Bulletin, v.52, p.969-987, 2006. Disponível em: <http://www. sciencedirect.com/science/article/pii/S0025326X06001408>. Acesso em: 19 maio, 2009. doi: 10.1016/j.marpolbul.2006.04.007.

MAANAN, M. Heavy metal concentrations in marine molluscs from the Moroccan coastal region. Environmental Pollution, v.153,p.176-183, 2008. Disponível em: $<$ http://www.sciencedirect. com/science/article/pii/S0269749107003995>. Acesso em: 10 set. 2011. doi: 10.1016/j.envpol.2007.07.024

MAGALHÃES, V.F. et al. Arsenic contamination and dispersion in the Engenho inlet, Sepetiba Bay, SE, Brazil. Water Air Soil Pollution, v.129, p.83-90, 2001. Disponível em: <http://www. springerlink.com/content/u3774178403h6236/>. Acesso em: 19 maio, 2009. doi: 10.1023/A:1010381902874.

MARIGOMEZ, I. et al. Cellular and subcellular distribution of metals in molluscs. Microscopy Research and Technique, v.56, p.358-392, 2002. Disponível em: $<$ http://onlinelibrary.wiley.com/ doi/10.1002/jemt.10040/abstract;jsessionid=5F6B9D6167711D

Ciência Rural, v.43, n.6, jun, 2013. 
8C2FB60DC861F436F6.d02t01>. Acesso em: 9 set. 2009. doi: $10.1002 /$ jemt. 10040 .

NAVAS-ACIEN, A. et al. Lead, Cadmium, smoking, and increased risk of peripheral arterial disease. Circulation, v.109, p.3196-3201, 2004. Disponível em: <http://circ.ahajournals.org/ content/109/25/3196.full.pdf + html $>$. Acesso em: 1 jun. 2012. doi: 10.1161/01.CIR.0000130848.18636.B2.

RAINBOW, P.S. Phyisology, physicochemistry and metal uptake: a crustacean perspective. Marine Pollution Bulletin, v.31, n.13, p.55-59, 1995. Disponível em: <http://www.sciencedirect. com/science/article/pii/0025326X95000058>. Acesso em: 10 jan. 2011. doi:10.1016/0025-326X(95)00005-8

RESGALLA, Jr C. et al. O mexilhão Perna perna (L.): biologia, ecologia e aplicações. Rio de Janeiro (RJ): Interciência, 2008. 324p.

SECRETARIA DE ESTADO DE MEIO AMBIENTE E DESENVOLVIMENTO SUSTENTÁVEL (SEMADS). Bacias hidrográficas e recursos hídricos da macrorregião 2: bacia da Baía de Sepetiba. Rio de Janeiro: SEMADS, 2001. 79p.

UNITED NATIONS ENVIRONMENT PROGRAMME (UNEP). Guidance for a global monitoring programme for persistent organic pollutants. Geneva (Switzerland): Inter-Organization Programme for the Sound Management of Chemicals, 2004. 105p.

WALLNER-KERSANACH, M.; BIANCHINI, A. Metais traço em organismos: monitoramento químico e de efeitos biológicos. In: BAPTISTA NETO, J.A. et al. Poluição marinha. Rio de Janeiro: Interciência, 2008. Cap.9, p.237-283.

ZAHIR, F. et al. Low dose mercury toxicity and human health. Environmental Toxicology and Pharmacology, v.20, p.351-360, 2005. Disponível em: <http://www.sciencedirect.com/science/ article/pii/S1382668905000700>. Acesso em: 1 jun. 2012. doi:10.1016/j.etap.2005.03.007. 